\title{
Long-run relative importance of temperature as the main driver to malaria transmission in Limpopo Province, South Africa - a simple econometric approach
}

\author{
Kibii Komen ${ }^{1 *}$, Jane Olwoch², Hannes Rautenbach ${ }^{1}$, Joel Botai ${ }^{1}$ and Adetunji Adebayo ${ }^{3}$ \\ ${ }^{1}$ Geoinformatics and Meteorology - Center for Environmental Studies, Department of Geography, University \\ of Pretoria, Pretoria, 0002, South Africa \\ ${ }^{2}$ SANSA Earth Observation, South African National Space Agency (SANSA), Pretoria, South Africa \\ ${ }^{3}$ Department of Town and Regional Planning, University of Pretoria, Pretoria, South Africa
}

*correspondence author: Kibii Komen Email: kibii.komen@gmail.com

\begin{abstract}
Malaria in Limpopo Province of South Africa is shifting and now observed in originally non-malaria districts and it is unclear whether climate change drives this shift. This study examines the distribution of malaria at district level in the province; determines direction and strength of the linear relationship and causality between malaria with the meteorological variables (rainfall and temperature) and ascertains their short and long run variations. Spatio-temporal method, Correlation analysis and econometric methods are applied. Time series monthly meteorological data (1998-2007) were obtained from South Africa Weather Services while clinical malaria data came from Malaria Control Centre in Tzaneen (Limpopo Province) and South African Department of Health. We find that malaria changes and pressures vary in different districts with a strong positive correlation between temperature with malaria, $r=0.5212$, and a weak positive relationship for rainfall, $r=0.2810$. Strong unidirectional causality runs from rainfall and temperature to malaria cases (and not vice versa): $\mathrm{F}(1,117)=3.89, \rho=0.0232$ and F $(1$, $117)=20.08, \rho<0.001$ and a bi-directional causality exists between rainfall and temperature and temperature to rainfall and from rainfall to temperature, $F(1,117)=$ 19.80; F $(1,117)=17.14$ with $\rho<0.001$ respectively in both cases. Results show evidence of strong existence of a long-run relationship between climate variables and malaria, with temperature maintaining very high level of significance than rainfall. Temperature, therefore, is more important in influencing malaria transmission in Limpopo Province.
\end{abstract}

Key words: Malaria, Climate change, Limpopo Province, Spatio-temporal, Causality, ARDL Model 


\section{INTRODUCTION AND PURPOSE}

Malaria is the most nagging parasitic infection affecting humans, accounting for an estimated 300-500 million cases of malaria worldwide with $90 \%$ of annual cases reported in sub-Saharan Africa (Reiter, 2008). A recent resurgence of malaria in the East African highlands involves multiple factors, ranging from climate and land use change, to drug resistance, variable disease control efforts, and other socio-demographic factors (Patz et al., 2002; Pascual et al., 2006). Malaria epidemics have long been reported to occur among vulnerable populations where immunity is often non-existent or poorly developed. It is estimated that epidemic malaria causes between $12 \%$ and $25 \%$ of estimated annual worldwide malaria deaths, including up to $50 \%$ of mortality in persons less than 15 years of age (Thomson et al., 2005).

Malaria is an extremely climate-sensitive disease (Rogers and Randolph, 2000) common in the tropics, (Patz and Olson, 2006), but also reported in mild-to-cold climates (Hulden, 2009). Rainfall and temperature anomalies are widely considered to be a major driver of inter-annual variability of malaria incidence in the semi-arid areas of Africa (Connor et al., 1999), and Thomson et al. (2005), recently recorded a warming trend in the East African highlands that corresponded with concomitant increases in malaria incidences (Pascual et al., 2006). Further, Siraj et al., (2014) provides evidence that an increase in the altitude of malaria distribution in warmer years will increases malaria burden in the densely populated highlands of Africa and South America. Ebi et al., 2005) studies on malaria in Zimbabwe assert that by 2050, the projected warming would make Zimbabwe's entire highland area climatologically more favourable to malaria. Large epidemics of malaria elsewhere have been associated with climate anomalies, such as in Colombia, the Indian subcontinent, and Uganda (Bouma and van der Kaay, 1996). Recently, it has been shown that in Botswana, indices of El Niño-related climate variability can serve as the basis of malaria risk prediction and early warning (Lindblade et al., 1999).

Empirical studies have reported rainfall (Githeko and Ndegwa, 2001; Thomson et al., 2005; Nkomo et al., 2006) and temperature (Paaijmans, 2010; Ngomane and de Jager, 2012) as the main climate factors that influence malaria transmission; however, other studies have included other variables such as humidity and vegetation (Haque et al., 2010;; Alemu et al., 2011). Recent sensitivity analysis by Lunde et al., (2013) of some malaria-transmitting anopheline mosquitoes of the Afrotropical region shows that relative humidity can be very important for malaria transmission. Rainfall provides condusive site conditions for mosquito breeding, and humidity and temperature together affects mosquito survival (Poveda et al., 2001).

Warmer temperatures shorten the mosquito life cycle, thereby increasing its population (Patz et al., 2005; Patz and Olson, 2006). High temperature shortens the development time of vector-borne pathogens; and combined with favourable climate conditions, the population of carrier-mosquitoes increases (Atul and Nettleman, 2005; Naqvi, 2009). Alongside drug resistance and land-use patterns, this increases the incidence of malaria (Harrus and Baneth, 2005; Pascual et al., 2006; IOM, 2008; Relman et al., 2008). Mordecai et al., (2013) concludes that as temperatures increase due to climate change, vector control will likely become more important, difficult and expensive in temperate areas but some warm areas may simply become too hot to support malaria. Studies report the most efficient and optimal transmission to occur at $25^{\circ} \mathrm{C}$ (Lunde et al., 2013, Mordecai et al., 
(2013), but at extreme high or low temperatures (above $28^{\circ} \mathrm{C}$ or below $16^{\circ} \mathrm{C}$ ), the cycle cannot be completed and transmission decreases dramatically or cannot occur ((Mordecai et al., 2013, Zucker, 1996; Williams et al., 1999)

In both theory and literature, variation in rainfall and temperature will affect observed malaria cases. Apart from climatic influence in malaria transmission, social and economic factors-e.g., population and migration-also play a significant role (Haines et al., 2000; van Lieshout et al., 2004). Moreover, a combination of mutating malaria parasites, resource constrains, and weak health systems, implies low adaptive capacity (Kovats and Haines, 2005).

South Africa has a warm climate, and much of the country experiences average annual temperatures of above $17^{\circ} \mathrm{C}$ (DST, 2010). M Malaria transmission is distinctly seasonal and limited to warm and rainy summer months. Case notifications generally increase from November, peak in late March to May, and then decline by the end of June. Craig et al. (2004) report that, in South Africa, the average seasonal pattern in malaria incidence follows periodicity in rainfall and temperature with a three to four month lag. Although we find this lag time rather long, elsewhere, the response time is not uniform. In the East African Highlands for example, Zhou et al. (2004) finds a one to two and two to five month lag for minimum and maximum temperature respectively, while Briet (2008) and Hashizume et al. (2009) report rainfall lag time of zero to three months and two to three months for Sri Lanka and Kenya, respectively.

Malaria is endemic in the low-altitude areas of South Africa at the border with Mozambique and Zimbabwe. Specifically, transmission is prevalent in three provinces: KwaZulu-Natal, Limpopo, and Mpumalanga province (Sharp et al., 1988; Gerritsen et al., 2008; Ngomane and de Jager, 2012; Kondo et al., 2002). Limpopo Province (Approximately 22-25ㅇ, 27-32ㅌ) lies in the low altitude area pre-disposed to malaria due to warm conditions. The occurrence of malaria cases in the province has been reported to be highly dependent on seasons (Bouma and van der Kaay, 1996).

Interventions through the malaria control program in South Africa rely heavily on the intermittent use of indoor residual spraying in periods shortly after heavy rains when malaria cases tend to rise. This program continues despite no empirical evidence that rainfall drives malaria in the province. Therefore, there is a need to establish the relative importance of rainfall and temperature in malaria transmission for effective malaria control. It is important to understand the relative importance, strengths, and direction of causality of climate-malaria drivers, as well as the role of rainfall and temperature as it relates to malaria dynamics in the short and long run. This is central in enhancing malaria control policy measures and informing the design of malaria early warning systems. Due to the fact that climate change by itself will increase vulnerability (Bohle et al., 1994;; van Lieshout et al., 2004), target planning is necessitated by careful consideration of all factors.

Despite reported reduction in malaria trends in South Africa through a combination of various social, economic, and policy efforts (Blumberg and Frean, 2007); the impact of recent climate change on malaria incidence remains poorly understood. Little is written about climate impacts on malaria in Limpopo Province. While Shewmake (2008) does not mention malaria in a study of household vulnerability to climate change, Gerritsen et al. 
(2008), on the other hand, provide only an overview of seasonal malaria incidence and mortality, and detect trends over time and places in the province.

This study uses Spatio-temporal, correlation, and econometric approaches (unit root tests and causality tests) to achieve the above aims. The spatial method examines the distribution of malaria at the district level within the province, while Pearson Correlation determines the direction and strength of the linear relationship between malaria with the meteorological variables. The econometric approach is applied to 1) validate and examine the intrinsic characteristics (stationarity) of malaria cases, rainfall, and temperature; 2) test the direction and relative strength of causation; and 3) ascertain the short run and long run equilibrium relationship of the variables. The strength of econometric methods lies in their ability to distinctively separate the effects of correlation from those that are related to causality, thereby eliminating the common fallacy that correlation implies causation. Causality is tested using the standard Granger Causality Test.

\section{Conceptual framework}

The conceptual framework for this study advances a multiple-factor explanation for malaria, ranging from climate and land use change, to drug resistance, variable disease control efforts, and other socio-demographic factors. Figure 1 below illustrates a simplified, non-detailed interrelationship. This study looks at the climate-malaria interrelationship.

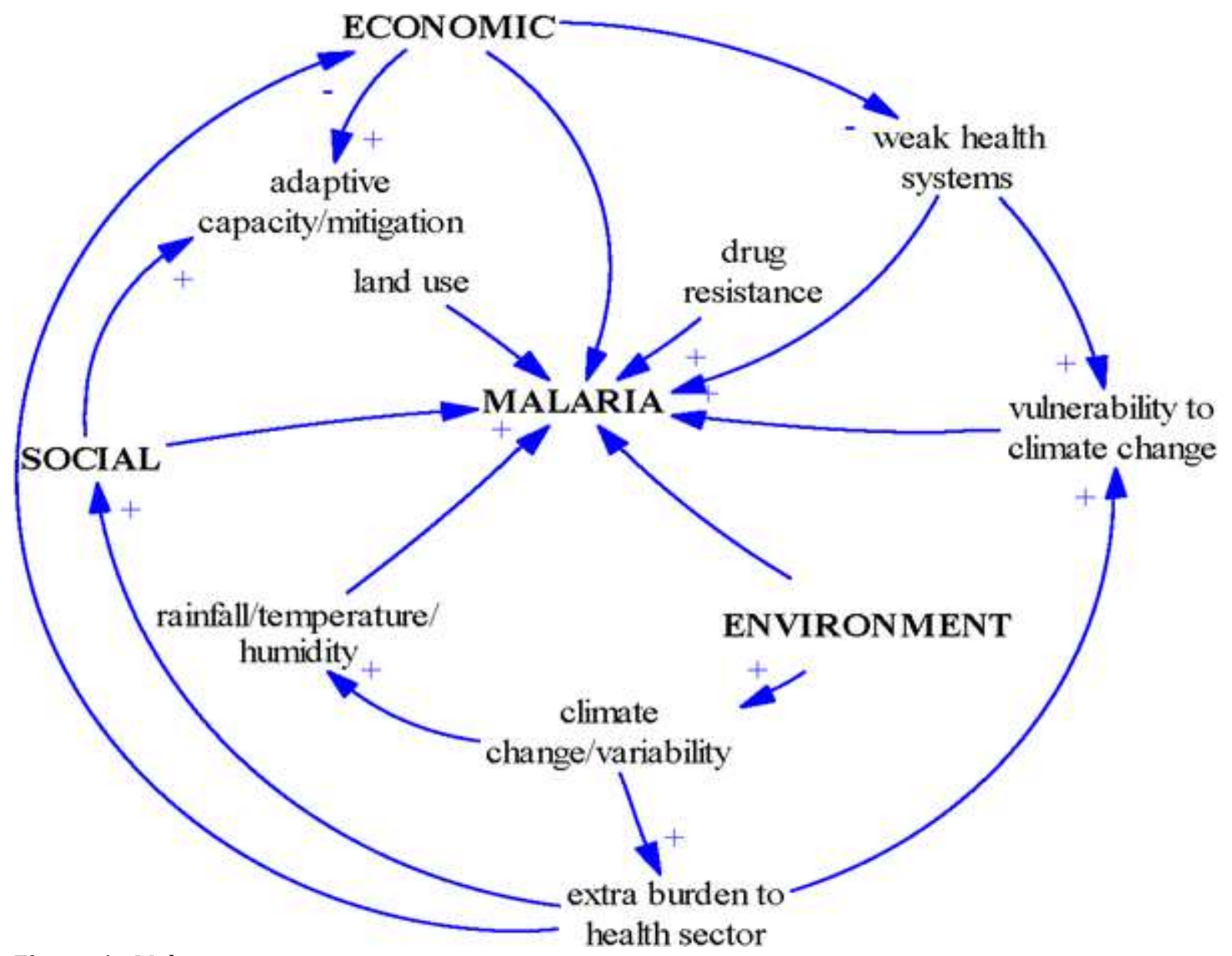

Figure 1 : Malaria-environment nexus 


\section{METHODS}

Data and sources

Monthly average rainfall and temperature along with the number of malaria cases from January 1998 to July 2007 are used. Climate data was obtained from the South Africa Weather Services, while malaria data were obtained from South African Department of Health and Malaria control Centre in Tzaneen, captured through passive and active surveillance systems. Details of the methods on how this data was collected can be obtained from Gerritsen et al. (2008).

Description of the methods

a. Spatio-temporal and correlation

The spatial distribution of malaria at municipality and district levels were mapped ArcGIS. Changes in the distribution were obtained using the Inverse distance weighted (IDW) interpolation method. IDW routine assumes that each measured point has a local influence that diminishes with distance. It gives greater weights to points closest to the prediction location, and the weights diminish as a function of distance. Malaria records for the various municipalities were spatially weighted and aggregated at the district level. Weighted points at the centroid of each district were then interpolated using the Inverse Distance Weighting model (Jorgensen et al., 2010; Messina et al., 2011; Hanafi-Bojd et al., 2012). The model assumes that the mapped variable decreases in influence with distance from its weighted location (Baltas, 2007). Given seasonalised climate variables, a linear relationship between temperature, rainfall, and malaria cases, can be derived from the Pearson Correlation coefficients as reported by Wilks (1995). The linear relationship between temperature and malaria cases with the influence of precipitation can be determined as a partial correlation Panofsky and Brier (1968) and Mardia et al. (1979).

\section{b. Econometric approaches}

\section{Causality}

In order to determine causality, Granger (1969) proposed a time series data-based approach. Intuitively, the standard Granger-causality test examines whether past changes in one variable, $y$, help to explain current changes in another variable, $x$, over and above the information provided by the lagged values of $x$. If not, then one concludes that " $y$ does not Granger-cause $x^{\prime \prime}$." To determine whether causality runs in the opposite direction, from $x$ to $y$, one basically repeats the experiment, but with the variables interchanged. The null hypothesis that $y$ does not Granger-cause $x$ is rejected if the coefficients in the equation are jointly significant based on the standard F-test.

There are three different types of situations in which a Granger-causality test can be applied and four possible feasible outcomes. The situations are: (i) a simple Grangercausality test with two variables and their lags; (ii) a multivariate Granger-causality test with more than two variables and; (iii) Granger-causality in a VAR framework. For the purposes of this study, we focus on the second situation (multivariate Granger-causality) since we have three variables: malaria cases, rainfall, and temperature. The four feasible outcomes are: 1) independence; here, neither malaria cases, rainfall, nor temperature, Granger-cause each other; 2) unidirectional Granger-causality where rainfall or 
temperature independently Granger-causes malaria cases, but not the other way round; 3) unidirectional Granger-causality where malaria cases cause rainfall or temperature independently, but not vice versa; and 4) bi-directional (or feedback) causality where malaria cases, rainfall, and temperature Granger-cause each other. Theoretically, it is expected that rainfall and temperature influence malaria cases. A bi-directional causality is expected between rainfall and temperature. We do not expect malaria cases to cause rainfall or temperature.

\section{Stationarity (unit root) test}

As a requirement for time series analysis, this paper first studies the univariate characteristics (stationarity) of rainfall, temperature, and malaria cases in this study using the standard Augmented Dickey-Fuller (ADF) (Dickey and Fuller, 1981) and Kwiatkowski, Phillips, Schmidt and Shin (KPSS) tests (Kwiatkowski et al., 1992). Stationarity is a process where the parameters of the process do not change with time; i.e., the mean, variance, and autocorrelations are constant in time, while the nonstationary variable is otherwise. A non-stationary variable can be transformed into a stationary process by either adjusting for trends or including a time index as an independent variable in the regression. Sometimes de-trending and inclusion of a time index may not be sufficient to make the series stationary due to the possibility that statistics for changes in the series between periods and seasons are constant, in which case, the data is differenced. Differencing implies transforming the variables into a series of period to period and/or season to season differences. A stationary series is denoted as I (0) but when the series is differenced once, it is said to be integrated to order one, i.e. I (1) and a twice difference is I (2).

In econometrics, testing for stationarity is an indispensable requirement for two main reasons. First, without stationarity tests, it is not possible to obtain any meaningful sample statistics such as means, variances, and correlations with other variables. Secondly, stationarity tests provide important clues in the search for an appropriate methodology and forecasting model. Although it is known from the literature that combining stationary variables with non-stationary variables in a regression model yields spurious (non-sensical) results and, therefore, an unreliable outcome (Komen and Kapunda, 2006; Gupta and Komen, 2009), models now exist that regresses both stationary and non-stationary data. The recourse lies in the recently developed Autoregressive Distributed Lag (ARDL)-Wald (Bounds) test framework by Pesaran and Shin (1995, 1999), Pesaran et al. (1996), and Pesaran (1997).

\section{Autoregressive Distributed Lag (ARDL)-Bounds Test Model}

The ARDL methodology is applicable in testing causation and long relationship in cases where not all variables are integrated to the same order. Cointegration (long-run relationship) is a situation where two or more series are non-stationary, but a linear combination of them is stationary. The advantage of using the ARDL-Bounds test in testing cointegration is that while the conventional cointegration method estimates the long-run relationships within the context of a system of equations, the ARDL method employs only a single reduced form equation (Pesaran and Shin, 1995). Most importantly, the ARDL framework avoids the larger number of specifications to be made in the standard cointegration test, such as decisions regarding the number of endogenous and exogenous variables to be included, the treatment of deterministic elements, as well as 
the optimal number of lags to be specified (Duasa, 2007). The procedure can be applied irrespective of whether the regressors are stationary or non-stationary, or mutually cointegrated (Pesaran et al., 2001).

\section{Model specification}

The ARDL specification takes the following form:

$$
\begin{aligned}
& \Delta \ln \text { mala }_{t}=\gamma+\sum_{i=0}^{\eta} \alpha_{i} \Delta \ln \text { rain }_{t-i}+\sum_{i=0}^{\eta} \delta_{i} \Delta \ln \text { temp }_{t-i}+\sum_{i=1}^{\eta} \varpi_{i} \Delta \ln \text { mala }_{t-i}+ \\
& \beta_{1} \ln \operatorname{rain}_{t-1}+\beta_{2} \ln \text { temp }_{t-1}+\beta_{3} \ln \text { mala }_{t-1}+\varepsilon_{t-1}(1)
\end{aligned}
$$

Where $\ln$ mala, $\ln$ rain and $\ln$ temp are natural logarithms of malaria cases, rainfall and temperature respectively; $\Delta$ denotes first difference operator; and $\eta$ is the optimal lag length.

The ARDL estimation proceeds in two steps. First is estimation of equation (1) by Ordinary Least Squares (OLS) in order to establish the existence of a long-run linear relationship. Once cointegration is confirmed, the second step is to estimate the long run coefficients (equation 2).

$\ln$ mala $_{t}=\gamma_{1}+\sum_{i=0}^{\eta} \alpha_{1 i} \ln \operatorname{rain}_{t-i}+\sum_{i=0}^{\eta} \delta_{1 i} \ln$ temp $_{t-i}+\sum_{i=0}^{\eta} \varpi_{1 i} \ln$ mala $_{t-i}+\varepsilon_{t-1}(2)$

The investigation of the long-run relationship using the ARDL approach involves the estimation of equation 2, through an Unrestricted Error Correction Model (UECM). Since specification assumes that the disturbances are serially uncorrelated, the choice of appropriate lag order is important (Sultan, 2010). The appropriate lag length in the ARDL model is selected by either Akaike Information Criterion (AIC) or the Schwarz Bayesian Criterion (SBC). The lag length that minimises SBC is selected. The unrestricted model is then estimated and progressively reduced, eliminating the statistically insignificant coefficients, and reformulating the lag structure where appropriate, to achieve orthogonality. The unrestricted ECM minimises the possibility of estimating spurious relations, while retaining the long-run information, suitable for economic interpretation (Greenidge et al., 2001). A battery of diagnostic tests can then be used to check the performance of the UECM (Akinboade et al., 2008; Hendry et al., 1984 in Sultan, 2010).

The short run dynamics is derived from the ARDL specification, equation (3), by constructing and Error Correction model (ECM), equation (4). 
$\Delta \ln$ mala $_{t}=\gamma_{2}+\sum_{i=1}^{\eta} \alpha_{2 i} \Delta \ln \operatorname{rain}_{t-i}+\sum_{i=0}^{\eta} \delta_{2 i} \Delta \ln$ temp $_{t-i}+\sum_{i=1}^{\eta} \varpi_{2 i} \Delta \ln$ mala $_{t-i}+$ $\sigma E C M_{t-1}+\varepsilon_{t-1}(3)$

Where ECM is the error correction term, defined as:

$E C M_{t}=\ln$ mala $_{t}-\gamma_{1}-\sum_{i=0}^{\eta} \alpha_{1 i} \ln$ rain $_{t-i}-\sum_{i=0}^{\eta} \delta_{1 i} \ln$ temp $_{t-i}-\sum_{i=0}^{\eta} \varpi_{1 i} \ln$ mala $_{t-i}(4)$

All coefficients of the short-run equation are coefficients relating to the short-run dynamics of the model's convergence to equilibrium, and $\sigma$ represents the speed of adjustment.

The $\mathrm{F}$ test is used to test the existence of long-run relationship. The null hypothesis $\left(\mathrm{H}_{0}\right)$ of no cointegration among variables in equation (1) is tested against an alternative hypothesis $\left(\mathrm{H}_{1}\right)$, presented below.

$$
\begin{aligned}
& H_{0}=\beta_{1}=\beta_{2}=\beta_{3}=0 \\
& H_{1}=\beta_{1} \neq \beta_{2} \neq \beta_{3} \neq 0
\end{aligned}
$$

The asymptotic distribution of the obtained F-statistic is nonstandard regardless of the degree of integration of the variables. This however, depends on whether (1) the variables included in the ARDL model are I ( 0 ) or I (1); (2) the number of regressors; (3) the model contains an intercept and/or a trend; and (4) the sample size. Two sets of critical F-values, representing the lower bound and the upper bound, have been provided by Pesaran and Shin (1999) for large samples. Narayan (2004) presents the critical $F$ values for sample size ranging 30-80. If the computed F-statistic for a chosen level of significance lies outside the critical bounds, a conclusive decision can be made regarding the cointegration of the regressors. If the statistic is higher than the upper bound, the null hypothesis of no cointegration can be rejected and the next step is to estimate the ARDL ECM where the short-run and long-run elasticities may be determined (Narayan 2004; Pesaran and Shin, 1999 in Sultan, 2010).

Computed and critical bounds of the F-Statistic are provided by (Pesaran et al., 2001). The F-statistics should lie outside the bounds for a long-run relationship to exist, but for shortrun, the coefficient of the error correction model (ECM) should be negative and statistically significant. 


\section{RESULTS}

In this section, we report spatial, correlation, time series, and short- and long-run results respectively.

Spatio-temporal and correlation results
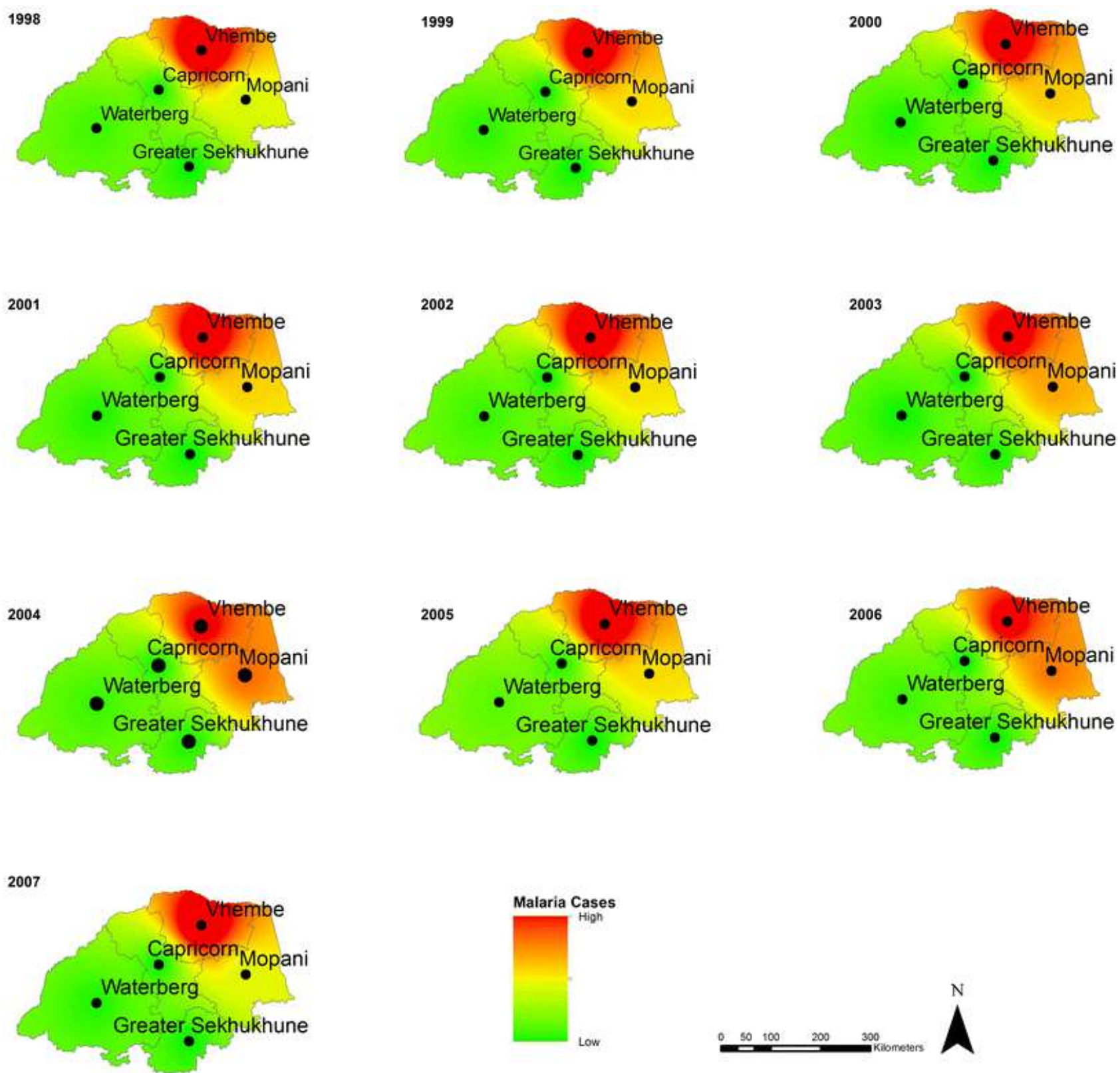

Figure 2 : Ten-year municipal and district spatial distribution of malaria in Limpopo Province

The number of malaria cases at the district level show that malaria is high in the Mopani and Vhembe districts throughout the study period of analysis, 1998 to 2007. The Vhembe district consistently shows more malaria cases. In the Mopani district on the other hand, malaria cases appear to be erratic, as shown on the maps. The overall trend shows that, whereas there were fewer cases in 1998, this was followed by a slight increase from 1999 to 2006. Very few cases were reported in Capricorn, Waterberg, and Greater Sekhukhune. 


\section{Correlation of rainfall and temperature with Malaria-A graphical outlook}

Malaria vs rain

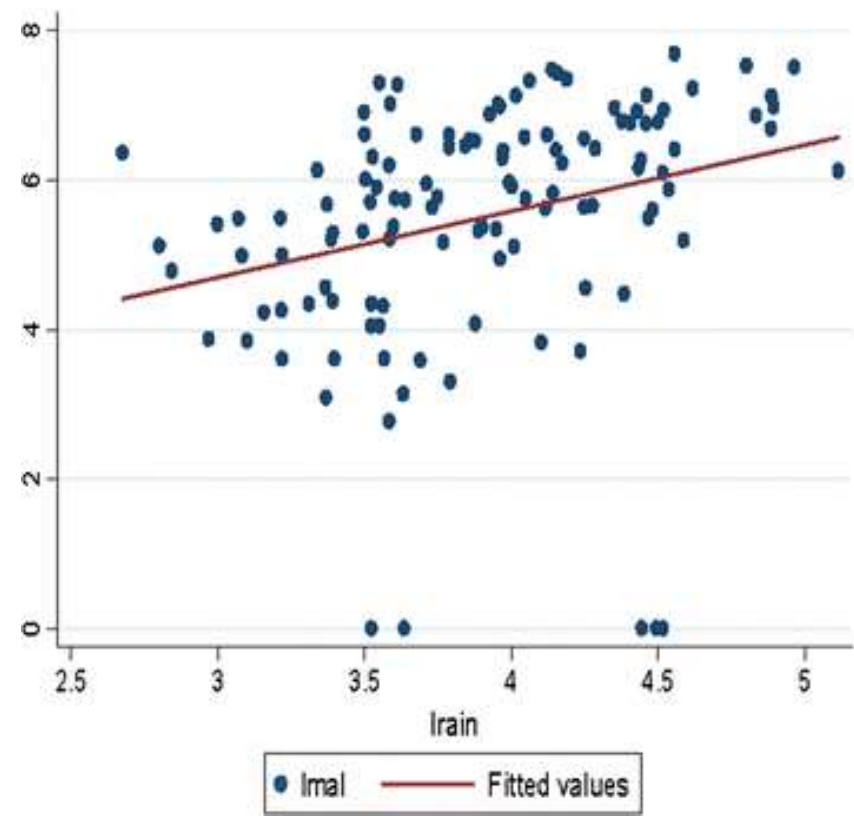

Malaria vs temperature

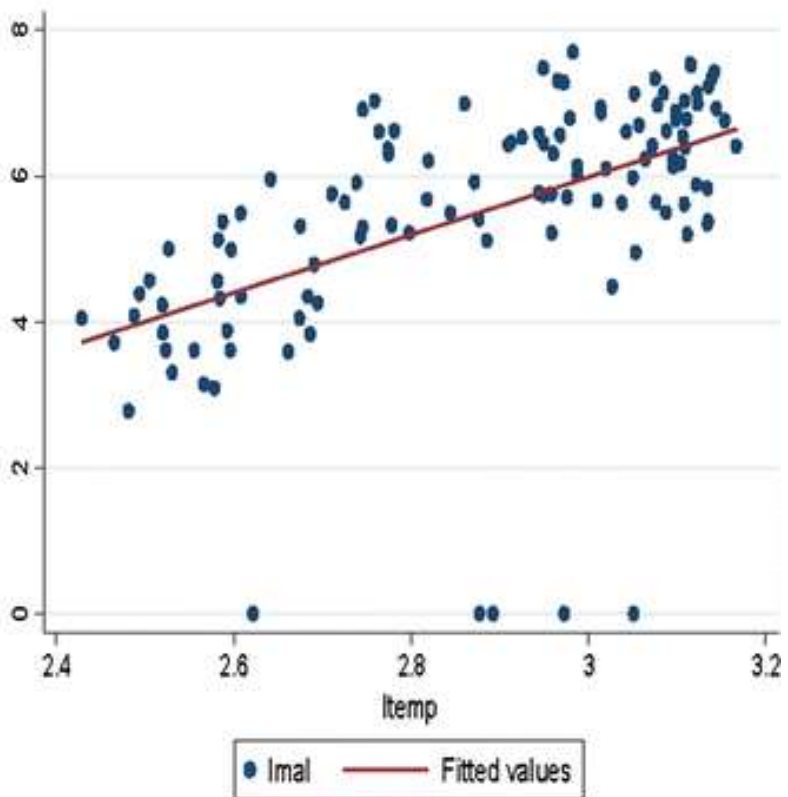

Figure 3 : Correlation of rainfall and temperature with malaria-a graphical outlook

Figure 3shows a scatter plot for rainfall and temperature with malaria cases. More observations are scattered away from the fitted line in the first panel (rainfall) than in the second panel (temperature). This indicates a high positive correlation with temperature than rainfall with an R-squared of $57.8 \%$.

Figure 4 illustrates the trend relationship between average rainfall and average temperature in relation to malaria cases.

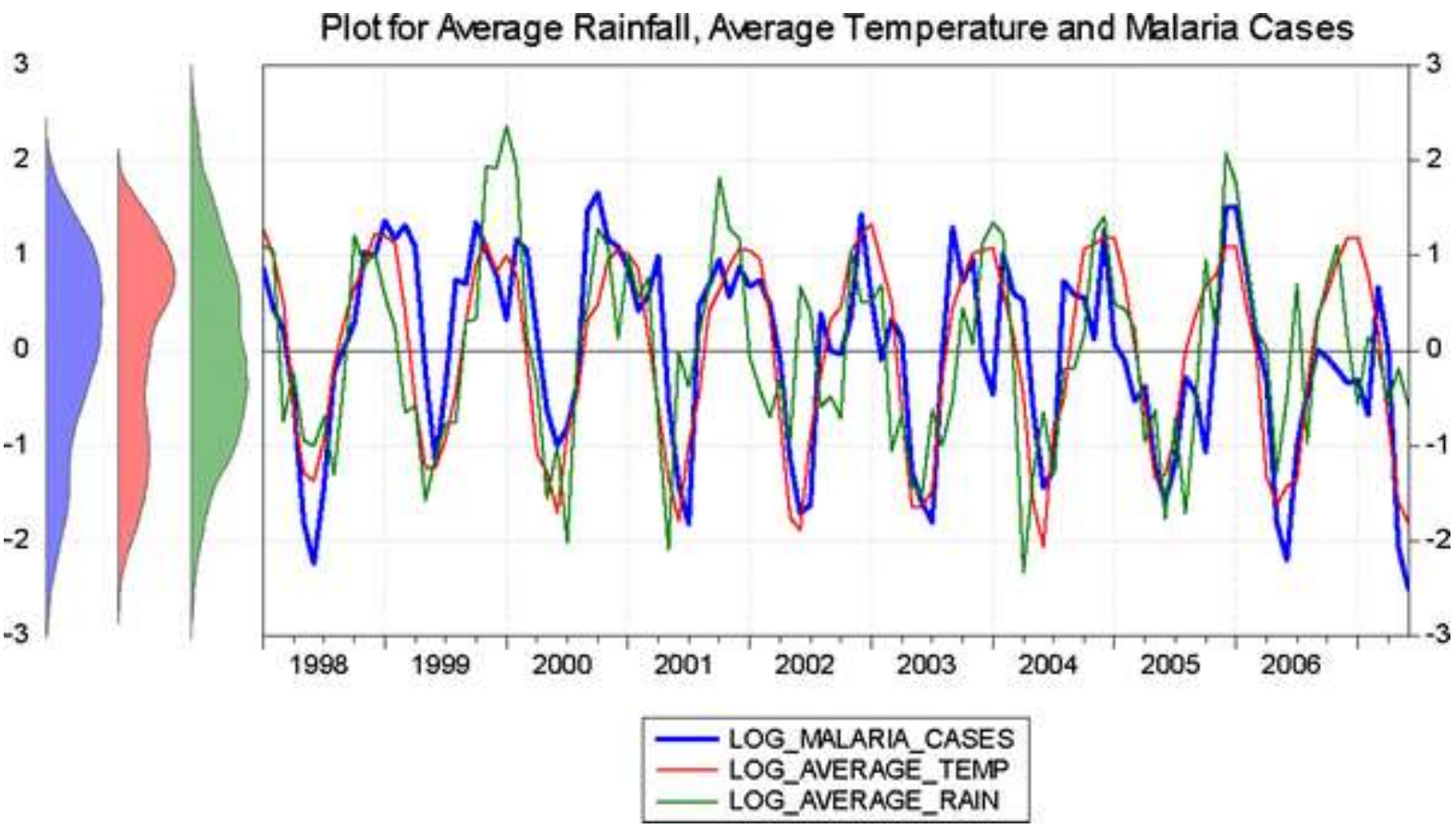

Figure 4 : Plot for average rainfall, average temperature, and malaria cases 
This reveals a very strong positive correlation between rainfall and temperature with malaria cases, although higher rainfall does not increase malaria cases significantly (e.g. 1999, 2001 and 2005). An increase in temperature is, however, consistent with an increase in malaria cases. The actual influence is further validated by statistics using the cross correlation method. This study finds a strong positive correlation of climate variables to malaria cases, with temperature exhibiting a stronger influence as compared to rainfall. The coefficient for temperature and rainfall is found to be 0.5212 and 0.2810 respectively.

Results for causal relationships

Table I presents Granger causality test results.

Table I : Causal Relationships.

\begin{tabular}{|c|c|c|c|c|}
\hline & $\begin{array}{l}\text { Pairwise granger causality tests } \\
\text { Date: 06/23/13 time: } 23: 50 \\
\text { Sample: } 1998 \mathrm{M01} 2007 \mathrm{M} 12 \\
\text { Lags: } 2\end{array}$ & & & \\
\hline & Null hypothesis & Obs & F statistic & Prob. \\
\hline (0) & RAINFALL does not Granger-cause Malaria & 117 & 3.89071 & 0.0232 \\
\hline (d) & MALARIA does not Granger-cause RAINFALL & 111 & 1.44730 & 0.2396 \\
\hline & TEMPERATURE does not Granger-cause MALARIA & & 20.0805 & $4 . \mathrm{E}-08$ \\
\hline (b & MALARIA does not Granger-cause TEMPERATURE & 11 & 0.07211 & 0.9305 \\
\hline & TEMPERATURE does not Granger-cause RAINFALL & 1 & 19.7996 & $4 . E-08$ \\
\hline (c) & RAINFALL does not Granger-cause TEMPERATURE & 11 & 17.1410 & $3 . \mathrm{E}-07$ \\
\hline
\end{tabular}

\section{a. Rainfall versus malaria cases}

We find a unidirectional causality from rainfall to malaria cases. For 117 observations, at a $5 \%$ significance level, the computed F-statistic is equal to 3.89071 with $\rho=0.0232$ implies that the null hypothesis that rainfall does not granger-cause malaria is rejected. Rainfall, therefore, influences malaria but reverse is not true. We do not reject the null hypothesis that malaria granger-causes rainfall since the F-statistic equal to 1.44730 with $\rho=0.2396$.

\section{b. Temperature versus malaria cases}

We also find a unidirectional causality from temperature to malaria cases. The computed F-statistic is 20.0805 with $\rho<0.001$ implying that reject the null hypothesis that temperature does not granger-cause malaria cases while from malaria cases to temperature, the-statistic is 0.07211 with $\rho>0.001$, implying malaria cases does not granger-cause temperature.

\section{c. Temperature versus rainfall}

This study finds a bi-directional causality between temperature and rainfall at a 1\% level of significance. The F-statistic for the causation from temperature to rainfall and from 
rainfall to temperature is 19.80 and 17.14 respectively with $\rho<0.001$ in both cases meaning that rainfall influences temperature and vice versa.

\section{Stationarity (unit root) results}

Table II is a summary of the stationarity test.

Table II : Unit Root Test Results.

\begin{tabular}{|c|c|c|c|c|c|c|}
\hline \multirow{2}{*}{ Test } & \multicolumn{2}{|c|}{ Log of malaria } & \multicolumn{2}{|c|}{ Log of rainfall } & \multicolumn{2}{|c|}{ Log of temperature } \\
\hline & Levels & \begin{tabular}{|l} 
First \\
difference
\end{tabular} & Levels & $\begin{array}{l}\text { First } \\
\text { difference }\end{array}$ & Levels & First difference \\
\hline $\mathrm{ADF}_{\mu}$ & & & $-7.926^{* * *}$ & & -2.252 & $-11.029^{* * *}$ \\
\hline $\mathrm{ADF}_{\tau}$ & $-4.283^{* * *}$ & & & & & \\
\hline $\mathrm{KPSS}_{\mu}$ & 0.620 & & $0.033^{* * *}$ & & $0.021^{* * *}$ & \\
\hline \multicolumn{7}{|l|}{$\mathrm{KPSS}_{\tau}$} \\
\hline Conclusion & $\begin{array}{l}\text { Stationary at } \\
\text { levels: I(0) }\end{array}$ & & $\begin{array}{l}\text { Stationary at } \\
\text { levels: I(0) }\end{array}$ & & $\begin{array}{l}\text { Non- } \\
\text { stationary }\end{array}$ & $\begin{array}{l}\text { Stationary at first } \\
\text { difference: I(1) }\end{array}$ \\
\hline
\end{tabular}

Computed ADF Augmented Dickey-Fuller (Dickey and Fuller 1981), KPSS Kwiatkowski, Phillips, Schmidst and Shin tests (Kwiatkowski et al. 1992).

* ,*, and ${ }^{* * *}$ Means significance at $10 \%, 5 \%$, and 1\%, respectively.

The results indicate that malaria and rainfall follow an autoregressive process with a unit root as the null hypothesis is rejected for these variables, while for temperature, the null hypothesis for existence of a unit root could not be rejected, implying that rainfall and malaria cases are stationary, while temperature is non-stationary.

\section{ARDL results}

\section{Short-run and long-run results}

These are results of estimating equation (1). This stationarity test result pointed to ARDL -Bounds Test as the appropriate methodology for analysis of the analysis of the short-run (in this case, variation within months) and long-run (variation in years) dynamics of rainfall and temperature as they relate to malaria. UECM results are summarised in Table III, following similar procedure by Hendry et al., (1984), and Akinboade et al., (2008). 
Table III : Unrestricted Error Correction Model.

\begin{tabular}{|l|l|l|}
\hline Variables & Coefficient & Standard error \\
\hline Constant & -3.158603 & 2.156372 \\
\hline D(LMALA(-2)) & -0.473095 & $0.123357^{* * *}$ \\
\hline D(LRAIN(-1)) & 0.745233 & $0.248330^{* * *}$ \\
\hline D(LTEMP(-1)) & 4.343676 & $1.129335^{* * *}$ \\
\hline LMALA(-1) & 0.249101 & $0.104620^{* *}$ \\
\hline LRAIN(-1) & -0.499685 & $0.300813^{*}$ \\
\hline
\end{tabular}

Diagnostic tests: Rampsey RESET $=2.271595$ (0.1350): null hypothesis that model has no omitted variable is not rejected implying no omitted variables in the model. White's test $=1.2668(0.3869)$. Null hypothesis of homoscedasticity is not rejected implying that variance of the variables in the model is homogeneous. Breusch-Godfrey LM test $=0.868$ (0.423). Null hypothesis of no serial correlation is not rejected implying that the model does not suffer from serial correlation.

Computed LMALA logarithm of malaria, LRAIN logarithm of rainfall, LTEMP logarithm of temperature, $(-1$ and -2 indicate lags).

$*, * *, * * *$ Means significance at $10 \%, 5 \%$, and $1 \%$, respectively.

The model passes all basic time series tests. There is no autocorrelation or serial correlation, no omitted variables; variance is homogeneous and residuals are normally distributed as confirmed by Durbin Watson statistic, Ramsey RESET test, BreuschGodfrey LM, White's test and Jarque-Bera test. The R-Squared for the UECM is 50\%, which indicates a relatively good and satisfactory fit in this case. The appropriate lag-length automatically selected by SBC is 3. Empirical studies report non-uniform lag time for malarial response to climatic variation. There seems to be an average malaria response within three months from the onset of the rainy season. Briet (2008) reports rainfall lag time of zero to three months, while Hashizume et al. (2009) report two to three months. Regarding temperature, Zhou et al (2004) finds minimum and maximum temperature lag time to be between one to two months and two to five months, respectively.

Bounds test (cointegration) results are presented in Table IV.

Table IV : Cointegration Properties.

\begin{tabular}{|c|c|c|c|}
\hline \multirow{2}{*}{ Dependent variable } & \multirow{2}{*}{ F stat } & \multicolumn{2}{|c|}{ Critical bounds (5\%) } \\
\hline & & Bottom & Top \\
\hline d (lmala) & 8.29 & 3.23 & 4.35 \\
\hline
\end{tabular}

$\mathrm{k}=3$. Computed, critical bounds are obtained from Narayan (2004). $\mathrm{d}$ (lmal) is the first difference of logarithm malaria.

The F-statistic is outside the critical bounds (8.29 lies outside $4.35_{\text {top }}$ and 3.23 bottom). We therefore reject the null hypothesis of no cointegration at a 5\% significance level, and conclude that a long-run relationship (cointegration) exists between malaria and the climatic variables.

The long-run relationship is reported in Table $\mathrm{V}$, while the short-run results are reported in Table VI. 
Table V : Long-Run Relationship Between Malaria Cases with Rainfall and Temperature.

\begin{tabular}{|l|l|l|}
\hline Variable & Coefficient & Standard error \\
\hline C & -6.155823 & $0.0006^{* * *}$ \\
\hline LRAIN & -0.373873 & 0.2648 \\
\hline LTEMP & 4.557185 & $0.0000^{* * *}$ \\
\hline
\end{tabular}

LRAIN the logarithm of rainfall, LTEMP logarithm of temperature.

*** Means significance at $1 \%$, respectively.

Table VI : Short-Run Relationship Between Malaria Cases with Rainfall and Temperature.

\begin{tabular}{l|l|l|}
\hline Variable & Coefficient & Standard error \\
\hline C & -0.080311 & 0.2668 \\
\hline D (LMALA(-2)) & -0.231066 & $0.0047^{* * *}$ \\
\hline D (LMALA(-3)) & -0.205359 & $0.0120^{* *}$ \\
\hline D (LRAIN) & -0.263281 & 0.1509 \\
\hline D (LTEMP(-1)) & 4.784184 & $0.0000^{* * *}$ \\
\hline Ecm t-1 & 0.005002 & 0.9783 \\
\hline -1 and -2 indicate lags. \\
LMALA logarithm of malaria, LRAIN logarithm of rainfall, LTEMP logarithm of temperature. \\
** and *** Mean significance at 5\% and 1\%, respectively.
\end{tabular}

In both short- and long-run instances, temperature maintains a very high level of significance: $4.784184(0.0000)$ and $4.557185(0.0000)$; while rainfall is low in both: 0.263281 (0.1509) and 0.373873 (0.2648).

\section{DISCUSSION}

We report GIS results of five districts (Capricorn, Greater Sekhukhune, Mopani, Waterberg, and Vhembe) in Limpopo Province. The Vhembe district consistently shows more malaria cases, while very few cases were reported in Capricorn, Waterberg, and Greater Sekhukhune throughout the period of analysis. In the Mopani district, malaria cases appear to be erratic. Spatial differences could be explained by socio-economic reasons, migration, malaria control programs, and even climate change. Understanding the differences in spatial distribution and areas burdened is crucial for targeted control measures.

In this study, rainfall and temperature are positively correlated with malaria, while temperature shows a stronger influence as compared to rainfall. We find the correlation coefficient of temperature and rainfall to be 0.5212 and 0.2810 respectively. Positive correlation between malaria and climate variables has been reported elsewhere. Rainfall: Huang et al. (2011); for Tibet: Briët et al. (2008), for Sri Lanka: Rainfall and temperature: Craig et al., (2004); Githeko and Ndegwa (2001) studies on Kenyan Highlands in Eastern Africa. Rainfall, temperature, humidity and vegetation cover: Haque et al., (2010) for Bangladesh. In Ghana, a positive correlation was found to exist between malaria and climate elements (Nkomo et al., 2006). The strength of the effect seems to flow from humidity to temperature and rainfall. This result is consistent with Huang et al. (2011), who found the correlation coefficient for Tibet to be 0.518 and 0.348 for temperature and rainfall respectively, concluding that temperature had a greater influence on malaria. 
Regardless of the greater influence of temperature, warming and rainfall would create the conditions for malaria vectors to thrive (Epstein et al., 1997), boost the population of disease-carrying mosquitos, and result in increased malaria epidemics (Lindsay and Martens, 1998; Nkomo et al., 2006). Increases in temperature generally accelerate vector life cycles, and also decrease the incubation period of the parasite (Kovats and Martens, 2000; Huang et al., 2011). However, at a very high temperature, the mosquito life cycle cannot be completed and transmission cannot occur (Zucker, 1996; Williams et al., 1999). It is interesting to observe a strong influence of temperature on malaria transmission in Limpopo; Ngomane and de Jager (2012), however, have reported rainfall as the main driver in the neighbouring Mpumalanga province.

The limitations of this study relates to the fact that temperatures in the study area is limited to a range on the curve where it is linear. Also, the study did not show whether year to year variations in malaria was driven by year to year variability in temperature/precipitation. This will be the focus of the forthcoming paper.

\section{CONCLUSION}

This paper has utilised spatial, correlation methods as well as bound testing approach to cointegration developed within an autoregressive distributed lag framework to test spatial malaria distribution at district levels, test the strength of correlation, and determine the existence of a long-run equilibrium relationship between climatic variables with malaria. There is strong evidence that climate influences malaria significantly both in the short and long run. We find that malaria pressure varies in different districts. We recommend (1) a study to ascertain the thresholds of temperature and rainfall under which malaria cases are probable; (2) the development and enhancement of early warning systems for malaria at the district level; (3) strengthening collaboration, partnership, and response integration with other principle sectors, such as meteorological departments; and finally,4, (4) long-term public health planning to combat malaria as a part of the key functions of the public health systems.

\section{REFERENCES}

1. Akinboade OA, Ziramba E, Kumo WL. (2008) The demand for gasoline in South Africa: An empirical analysis using co-integration techniques. Energy Economics 30: 3222-3229

2. Alemu A, Abebe G, Tsegaye W, Golassa Lemu (2011) Climatic variables and malaria transmission dynamics in Jimma town, South West Ethiopia. Parasites \& Vectors 4:30

3. Atul K, Nettleman, M (2005) Global warming and infectious disease Archives of Medical Research 36: 689-696.

4. Baltas E (2007) Spatial distribution of climatic indices in northern Greece. Meteorological Applications 14: 69-78.

5. Bayoh MN, Linsay SW (2004) Temperature-related duration of aquatic stages of the Afrotropical malaria vector mosquito Anopheles gambiae in the laboratory Medical and Veterinary Entomology 18, 174-179 
6. Blumberg L, Frean J (2007) Malaria control in South-Africa - challenges and successes. South African Med. Journal 97:1193-1197.

7. Bohle HG, Downing TE, Watts MJ (1994) Climate change and social vulnerability: Toward a sociology and geography of food insecurity. Global Environmental Change 4(1): 37-48.

8. Bouma MJ and van der Kaay HJ (1996) The El Niño/Southern Oscillation and the historic malaria epidemics on the Indian subcontinent and Sri Lanka: an early warning system for future epidemics? Trop. Med. Int. Health 1: 86-96.

9. Briet J, Vounatsou P, Gunawardena D, Galappaththy N, Amerasinghe P (2008) Temporal correlation between malaria and rainfall in Sri Lanka. Malar J 7: 77.

10. Connor S, Thomson M, Molyneux D (1999) Forecasting and prevention of epidemic malaria: new perspectives on an old problem. Parassitologia 41: 439-448.

11. Craig MH, Kleinschmidt I, Nawn JB, Sueur DL, Sharp BL (2004) Exploring 30 years of malaria case data in KwaZulu-Natal, South Africa: Part I. The impact of climatic factors; Tropical Medicine and International Health Vol 9 (12) 1247-1257

12. Department of Science and Technology (DST) (2010). South African Risk and Vulnerability Atlas.

13. Dickey DA, Fuller WA (1981) Likelihood ratio statistics for autoregressive time series with a unit root. Econometrica 49: 1057-1072.

14. Duasa J (2007) Determinants of Malaysian trade balance: an ARDL Bound Testing approach. Journal of Economic cooperation, 28 (3), 21-40.

15. Ebi KL, Hartman J, Chan N, McConnell KJ, Schlesinger M, Weyant J (2005) Climate suitability for stable malaria transmission in Zimbabwe under different climate change scenarios. Climate Change 73: 375-393.

16. Epstein PR, Diaz HF, Elias SA, Grabherr G, Graham NE, Martens WJM, MosleyThompson E, Susskind J (1997) Biological and physical signs of climate change: focus on mosquito-borne diseases. Bulletin of the American Meteorological Society 78: 409-417.

17. Gerritsen AAM, Kruger P, Schim van der Loeff MF, Grobusch MP (2008) Malaria incidence in Limpopo Province, South Africa, 1998-2007. Malaria Journal 7:162; doi:10.1186/1475-2875-7-162

18. Githeko AK, Ndegwa W (2001) Predicting Malaria Epidemics in the Kenyan Highlands Using Climate Data: A Tool for Decision Makers. Global Change \& Human Health 2 (1): 54-63; DOI: 10.1023/A:1011943131643

19. Granger, CJ (1969) Investigating Causal Relationships by Econometrics Models and Cross Spectral Methods. Econometrica. Vol. 37, pp. 425-435.

20. Greenidge K, Holder C, Mayers S (2009) Estimating the Size of the informal economy in Barbados. Business, finance and emerging economies 4(1)

21. Gupta R and Komen K (2009) Time Aggregation and the Contradictions with Causal Relationships: Can Economic Theory Come to the Rescue? Studies in Economics and Econometrics. 33: 13 - 24 ISSN: 03796205

22. Haines A, McMichael AJ, Epstein PR (2000) Environment and health: 2. Global climate change and health. Canadian Med. Association Journal 163 (6)

23. Hanafi-Bojd AA, Vatandoost H, Oshaghi MA, Charrahy Z, Haghdoost AA, Zamani G, Abedi F, Sedaghat MM, and Soltani M, Shahi M and, Raeisi A (2012) Spatial analysis and mapping of malaria risk in an endemic area, south of Iran: A GIS based decision making for planning of control. Acta Tropical 122(1): 132-137. 
24. Haque U, Hashizume M, Glass GE, Dewan AM, Overgaard HJ, Yamamoto T (2010) The Role of Climate Variability in the Spread of Malaria in Bangladeshi Highlands. PLoS ONE 5(12): e14341. doi:10.1371/journal.pone.0014341

25. Harrus S, Baneth G (2005) Drivers for the emergence and reemergence of vectorborne protozoa land bacterial diseases. International Journal of Parasitology. 35: 11-12):1309-1318.

26. Hashizume M, Terao T, Minakawa N (2009) The Indian Ocean Dipole and malaria risk in the highlands of western Kenya. Proc Natl Acad Sci USA 106: 1857-1862.

27. Hendry DF, Pagan A, Sargan JD (1984) Dynamic specification. In: Griliches, Z. Intrilligator, M. (Eds.), Handbook of Econometrics. vol. 2. North Holland, Amsterdam.

28. Huang F, Zhou S, Zhang S, Wang H, Tang L (2011) Temporal correlation analysis between malaria and meteorological factors in Motuo County, Tibet. Malaria Journal 10:54; doi:10.1186/1475-2875-10-54

29. Hulden L and Hulden (2009)The decline of malaria in Finland - the impact of the vector and social variables Malaria Journal 8:94 doi:10.1186/1475-2875-8-94

30. IOM. 2008. Vector-borne diseases: Understanding the environmental, human health and ecological connections. Washington, DC: The National Academies Press.

31. Jorgensen P, Nambanya S, Gopinath D, Hongvanthong B, Luangphengsouk K, Bell D, Phompida S and Phetsouvanh R (2010) High heterogeneity in Plasmodium falciparum risk illustrates the need for detailed mapping to guide resource allocation: a new malaria risk map of the Lao People's Democratic Republic. Malaria Journal 9(59); doi: 10.1186/1475-2875-9-59.

32. Komen DK, Kapunda SM (2006) Macroeconomic determinants of poverty reduction in the era of globalisation in Kenya: Policy implications. African Journal of Economic policy 13 (2). December. ISSN 1116-4875.

33. Kondo H, Seo N, Yasuda T, Hasizume M, Koido Y, Ninomiya N, Yamamoto Y (2002) Post-flood infectious diseases in Mozambique. PrehospDisast Med. 17(3):126133.

34. Kovats RS, Haines A (2005) Global climate change and health: recent findings and future steps. Canadian Medical Association Journal 172(4):501-502.

35. Kovats RS, Martens P (2000) Human health. In: Assessment of Potential Effects and Adaptations for Climate Change in Europe: The Europe ACACIA Project [Parry, M.L. (Ed.)]. Jackson Environment Institute, University of East Anglia, Norwich, United Kingdom, pp. 227-242.

36. Kwiatkowski D, Phillips PCB, Schmidt P, Shin Y (1992) Testing the Null Hypothesis of Stationarity against the Alternative of a Unit Root. Journal of Econometrics 54: 159-178.

37. Landman WA, Goddard L (2005) Predicting southern African summer rainfall using a combination of MOS and perfect prognosis. Geophys. Res. Lett. 32, L15809; doi: 10.1029/2005GL022910.

38. Lindblade KA, Walker ED, Onapa AW, and Katungu J, Wilson ML (1999) Highland malaria in Uganda: prospective analysis of an epidemic associated with El Nino. Trans. R. Soc. Trop. Med. Hyg. 93: 480-487.

39. Lindsay SW, Martens WJM (1998) Malaria in the African highlands: past, present and future. Bulletin of the World Health Organization, 76:33-45.

40. Lunde TM, Bayoh MN, and Lindtjørn B (2013)How malaria models relate temperature to malaria transmission Parasites \& Vectors 6:20 
41. Lunde TM, Korecha D, Loha E, Sorteberg A and Lindtjørn B (2013) A dynamic model of some malaria-transmitting anopheline mosquitoes of the Afrotropical region. I. Model description and sensitivity analysis. Malaria Journal 12:28

42. Mardia K, Kent J, Bibby J (1979) Multivariate analysis. Academic Press, London 518.

43. Messina JP, Taylor SM, Meshnick SR, Linke, AM, Tshefu AK, Atua B, Mwandagalirwa K, Emch M (2011) Population, behavioural and environmental drivers of malaria prevalence in the Democratic Republic of Congo. Malaria Journal 10 (161); doi: 10.1186/1475-2875-10-161.

44. Mordecai EA, Paaijmans KP, Johnson LR, Balzer C, Ben-Horin T, Moor E, McNally Amy, Pawar S, and Ryan SJ, Smith TC. 1 and Lafferty (2013) Optimal temperature for malaria transmission is dramatically lower than previously predicted. Ecology Letters, 16: 22-30 doi: 10.1111/ele.12015

45. Naqvi ZR (2009) Using remote sensing to assess potential impacts of hurricanes on mosquito habitat formation: Investigating the mechanisms for interrelationship between climate and the incidence of vector-borne diseases. Theses/DissertationsEnvironmental Studies. Submitted to the Graduate Faculty of Baylor University.

46. Narayan PK (2004) Reformulating critical values for the bounds F-statistics approach to cointegration: An application to the tourism demand model for Fiji. Department of Economics 2004 Discussion Papers no.02/04. Monash University, Melbourne, Australia.

47. Ngomane L, de Jager C (2012) Changes in malaria morbidity and mortality in Mpumalanga Province, South Africa (2001- 2009): A retrospective study. Malaria Journal 11:19

48. Nkomo JC, Nyong AO, Kulindwa, K (2006). The Impacts of Climate Change on Africa. Final Draft Submitted to: The Stern Review on the Economics of Climate Change.

49. Paaijmans KP, Blanford S, Bell AS, Blanford JI, Read AF. Thomas MB (2010) Influence of climate on malaria transmission depends on daily temperature variation. PNAS 107 (34): 15135-15139

50. Panofsky HA, Brier GW (1968) Some applications of statistics to Meteorology. The Pennsylvania State University, University Park, Pennsylvania 224.

51. Pascual M, Ahumada JA, Chaves LF, Rodo' X, Bouma M (2006) Malaria resurgence in the East African highlands: Temperature trends revisited. Proc. Natl. Acad. Sci. USA 103, 5829-5834.

52. Patz JA, Campbell-Lendrum D, Holloway T, Foley JA (2005) Impact of regional climate change on human health. Nature 438, 310-317 | doi: 10.1038/nature04188

53. Patz JA, Hulme M, Rosenzweig C, Mitchell TD, Goldberg RA, Githeko AK, Lele S, McMichael AJ, Le Sueur D (2002) Climate change: Regional warming and malaria resurgence. Nature 420:627-628. Discussion 628.

54. Patz JA, Olson SH (2006) Malaria risk and temperature: Influences from global climate change and local land use practices. Ann Trop Med Parasitol. 100(56):535-49.

55. Pesaran MH, Shin Y (1999) An autoregressive distributed lag modelling approach to cointegration analysis. In: Strøm S, editor. Econometrics and economic theory in the twentieth century: the Ragnar Frisch Centennial Symposium.Cambridge: Cambridge University Press.

56. Pesaran MH, Shin Y, Smith RJ (2001) Bounds testing approaches to the analysis of level relationships. Journal of Applied Econometrics 16: 289-326 
57. Poveda G, Rojas W, Quinones ML, Velez ID, Mantilla RI, Ruiz D, Zuuaga JS, Rua GL (2001). Coupling between annual and ENSO timescales in the malaria-climate association in Colombia. Environ. Health Perspect. 109:489-493.

58. Reiter P (2008) Global warming and malaria: knowing the horse before hitching the cart. Malaria Journal 7 (Suppl 1):S3 doi:10.1186/1475-2875-7-S1-S3

59. Relman DA, Hamburg MA, Choffnes ER, Mack A (2008) Global Climate Change and Extreme Weather Events: Understanding the Contributions to Infectious Disease Emergence: Workshop Summary. ISBN: 0-309-12403-4, 304 pages, 6 x 9.

60. Rogers DJ, Randolph SE (2000) The global spread of malaria in a future, warmer world. Science, 289:1763-1766.

61. Sharp BL, Ngxongo S, Botha MJ, Ridl FC, Le Sueur D (1998) An analysis of 10 years of retrospective malaria data from the KwaZulu areas of Natal. South African Journal of Science 84,102-106.

62. Shewmake S (2008) Vulnerability and the Impact of Climate Change in South Africa's Limpopo River Basin. IFPRI Discussion Paper 00804

63. Siraj AS, Santos-Vega M , Bouma MJ, Yadeta D, Carrascal DR , Pascual M (2014) Altitudinal Changes in Malaria Incidence in Highlands of Ethiopia and Colombia Science 7 March 2014: Vol. 343 no. 6175 pp. 1154-1158. doi: $10.1126 /$ science. 1244325

64. Sultan R (2010) Short-run and long-run elasticities of gasoline demand in Mauritius: an ARDL bounds test approach. Journal of Emerging Trends in Economics and Management Sciences 1 (2): 90-95

65. Thomson MC, Mason SJ, Phindela T, Connor SJ (2005) Use of Rainfall and Sea Surface Temperature Monitoring for Malaria Early Warning in Botswana: Am. J. Trop. Med. Hyg. 73(1): 214-221

66. van Lieshout M, Kovats RS, Livermore MTJ, Martens P (2004) Climate change and malaria: Analysis of the SRES climate and socio-economic scenarios. Global Environmental Change 14(1): 87-99

67. WHO, (2001) Malaria Early Warning Systems, Concepts, Indicators and Partners. A framework for Field Research in Africa. 1--84, Report no. WHO/CDS/RBM/ 2001.32 (WHO/Roll Back Malaria/Technical Support Network for Prevention and Control of Malaria, Geneva)

68. Wilks, DS (1995) Statistical methods in the atmospheric sciences. International Geophysics Series. 59: 469.

69. Williams HA, Roberts J, Kachur SP, et al. (1999) Malaria surveillance-United States, 1995. Morbidity and Mortality Weekly Report. vol. 48, no. 1, pp. 1-23.

70. Zhou G, Minakawa N, Andrew K, Guiyun Y (2004) Association between climate variability and malaria epidemics in the east African highlands. Proc Natl Acad Sci USA 101: 2375-2380.

71. Zucker JR (1996) Changing patterns of autochthonous malaria transmission in the United States: a review of recent outbreaks. Emerging Infectious Diseases. vol. 2, no. 1, pp. 37-43. 